\title{
INFLUENCIA DA TEMPERATURA DE EMBEBIÇÃO DA SEMENTE DE SOJA NO TESTE DE CONDUTIVIDADE ELÉTRICA PARA AVALIAÇÃO DA QUALIDADE FISIOLÓGICA ${ }^{1}$
}

\author{
LUZINEIDE F. DE CARVALHO², CARLOS SIGUEYUKI SEDIYAMA³ ${ }^{3}$ MÚCIO SILVA REIS ${ }^{4}$, \\ DENISE C. F. S. DIAS ${ }^{4}$, MAURÍLIO A. MOREIRA 5 .
}

\begin{abstract}
RESUMO - O presente trabalho teve como avaliar o efeito de diferentes temperaturas na redução do período de embebição de sementes de soja no teste de condutividade elétrica. Utilizaram-se sementes colhidas no estádio R8 e aos 15, 30 e 45 dias após R8, as quais foram armazenadas em câmara fria até a realização dos testes de avaliação da qualidade fisiológica. No teste de condutividade elétrica, foi estudada a metodologia tradicional, com quatro repetições de 50 sementes embebidas em água na temperatura de $250 \mathrm{C}$ por 24 horas e duas outras metodologias, constituídas de 20 repetições de 10 sementes com tempo de embebição de 10, 30, 60 e 120 minutos nas temperaturas de 32oC ou de 40oC. Pelos resultados obtidos observou-se que a elevação da temperatura diminuiu o tempo de embebição para identificação de sementes de soja com diferentes níveis de vigor; o teste de condutividade elétrica a 32 ou 40oC por 10, 30, 60 e 120 minutos é eficiente na avaliação rápida da qualidade das sementes de soja; o período de 10 minutos de embebição a 32 ou 40oC, já possibilita a separação de lotes de sementes pelo teste de condutividade elétrica.
\end{abstract}

Termos para indexação: Glicine max, vigor, período de embebição

\section{INFLUENCE OF SOAKING TEMPERATURE OF SOYBEAN SEEDS IN THE ELECTRIC CONDUCTIVITY TEST TO EVALUATE PHYSIOLOGICAL QUALITY}

\begin{abstract}
The objective of this research was to evaluate the effect of temperature on the reduction in the soaking period of soybean seeds for the electric conductivity test. Seeds were harvested at the R8 stage and 15, 30 and 45 days after R8 and stored in a cold room until physiological quality tests were performed. The electric conductivity test was carried out using the traditional methodology, with four replications of 50 seeds imbibed in water at 250C for 24 hours, and two other methodologies consisting of 20 replications of 10 seeds imbibed for 10, 30, 60 and 120 minutes at 32oC or 40oC. The results indicated that the increase in the soaking temperature decreases the soaking period to identify soybean seeds with different vigor levels; the electric conductivity test at 32 or 40oC for 10, 30, 60 and 120 minutes is efficient for rapid evaluation of soybean seed quality and the soaking period of 10 minutes at 32 or $40 \mathrm{oC}$ already permits classification of seed lots according to theirs vigor level by the electric conductivity test.
\end{abstract}

Index terms: Glicine max, vigor, soaking period.

${ }^{1}$ Submetido em 01/08/2008. Aceito para publicação em 19/02/2008. Parte da Tese de Doutorado da primeira autora apresentada a UFV.

${ }^{2}$ Eng. Agr., D.Sc., bolsista-DCR, Embrapa Meio-Norte. CEPE 64006-220, Teresina, PI, Brasil. luzineidecarvalho@yahoo.com.br. ${ }^{3}$ Eng. Agr ${ }^{\circ}$., Ph.D., Professor Titular, Dep. de Fitotecnia, UFV. CEP 36571-000 Viçosa, MG,
Brasil. Cssediyama@ufv.br.

${ }^{4}$ Eng. Agr., D.Sc., Professor Titular, Dep. de Fitotecnia, UFV. msreis@ ufv.br; dcdias@ufv.br. 5Eng. Agro.., Ph.D., Professor Titular, Dep. de Bioquímica e Biologia Molecular, UFV. moreira@ufv.br 


\section{INTRODUÇÃO}

A utilização de métodos rápidos, confiáveis e de fácil execução para estimar a viabilidade das sementes, já é uma necessidade nas instituições de pesquisa, empresas e laboratórios de análises de sementes, devido às vantagens proporcionadas pela rapidez dos resultados nos diversos segmentos de produção. O descarte de lote de sementes de qualidade inadequada, já na recepção ou no beneficiamento favorece a redução de um acondicionamento desnecessário.

Os testes rápidos mais estudados estão relacionados com eventos iniciais da seqüência de deterioração das sementes, como a degradação das membranas celulares e a redução das atividades respiratórias e biossintéticas (Delouche e Baskin, 1973). Dentre os quais, destaca-se o teste de condutividade elétrica que avalia indiretamente o grau de estruturação das membranas celulares, em decorrência da deterioração das sementes, por meio da determinação da quantidade de íons lixiviados em solução de embebição (Vieira e Krzyzanowski, 1999).

Durante a secagem natural da semente no processo de maturação, as membranas celulares sofrem um processo de desorganização estrutural, estando tanto mais desorganizadas quanto menor o teor de água na semente (Bewley, 1986), perdendo, temporariamente, a sua integridade organizacional (Simon e Raja-Harum, 1972).

Na fase inicial do processo de embebição, a capacidade de a semente reorganizar o sistema de membranas celulares e reparar danos físicos e, ou, biológicos, que podem ter ocorrido durante o processo de produção, irá influenciar a quantidade e a natureza de lixiviados liberados para o meio externo (Vieira e Krzyzanowski, 1999). Assim, quanto maior a velocidade de restabelecimento da integridade das membranas, menor será a quantidade de lixiviados liberados para o meio externo e, conseqüentemente, maior o vigor da semente. $\mathrm{O}$ valor da condutividade elétrica da solução de embebição das sementes varia em quantidade e tipo de lixiviados, como açúcares, aminoácidos, ácidos graxos, enzimas e íons inorgânicos, como $\mathrm{K}^{+} \mathrm{Ca}^{++}, \mathrm{Mg}^{++}$e $\mathrm{Na}^{+}$(Vieira, 1994).

Vários fatores podem interferir nos resultados do teste de condutividade elétrica e, conseqüentemente, na sua interpretação. Entre esses, estão o genótipo dentro de uma espécie e, ou, cultivar (Panobianco e Vieira, 1996); a desestruturação das membranas (Powell, 1986); o tamanho da amostra (Hampton et al., 1992); a temperatura de embebição (Vanzolini e Nakagawa, 1999a); o período de embebição (Loeffler et al.; 1988; Dias e Marcos Filho, 1996); a integridade de sementes danificadas fisicamente
(Tao, 1980); o número de sementes constituintes da amostra avaliada (Hampton et al., 1994), embora, dentro de certos limites, as interferências sejam pequenas ou inexistentes.

Esses fatores têm sido alvos de pesquisas na busca por resultados mais consistentes, principalmente o período de embebição que é considerado um fator de extrema importância na rapidez de execução e padronização desse teste. A maioria dos trabalhos tem recomendado o período de 24 horas de embebição para que se proceda à leitura de condutividade elétrica na água de embebição das sementes consideradas graúdas, como ervilha (Caliari e Marcos Filho, 1990), milho (Bruggink et al., 1991) e soja (Aosa, 1983; Krzyzanowski et al., 1991; Vieira, 1994), período esse considerado adequado para a rotina normal dos laboratórios de análise de sementes. No entanto, várias pesquisas têm apontado para a possibilidade de redução desse período, tendo em vista que períodos menores de tempo foram capazes de discriminar lotes de sementes de soja com níveis distintos de vigor (Loeffler et al., 1988; Marcos Filho et al.,1990 e Dias e Marcos Filho 1996). Pesquisas, visando adequar o teste de condutividade elétrica a determinada espécie, têm constatado, também, redução no período de embebição para avaliação da qualidade de sementes. Em sementes de milho, valores de condutividade elétrica tomados com oito horas foram os que melhor classificaram as sementes quanto aos danos pela secagem (Rosa et al., 2000). Vanzolini e Nakagawa (1999b) observaram em sementes de amendoim que em três horas de embebição foi possível separar os lotes de qualidade inferior, dentre os avaliados. Em milheto, o tempo de duas horas mostrou-se promissor para realização do teste (Gaspar e Nakagawa, 2002).

A temperatura para embebição, tradicionalmente adotada, é a de $25^{\circ} \mathrm{C}$, por ser a mais coerente com as condições ambientais dos laboratórios de análises de sementes (Vieira e Krzyzanowski, 1999). Segundo Murphy e Noland, (1982) a temperatura durante a embebição das sementes influencia diretamente a velocidade de embebição e a lixiviação de eletrólitos no interior das células para o meio externo. O efeito da elevação da temperatura de embebição sobre a lixiviação ocorre basicamente sobre a quantidade e a velocidade de perda de lixiviados. Os valores da condutividade elétrica aumentaram, com a elevação da temperatura de embebição para sementes de soja, de feijão-comum e de feijão-mungo (Hampton et al., 1992). De acordo com Leopold (1980) a elevação da temperatura altera os valores de condutividade elétrica, mas não, necessariamente, a classificação dos lotes.

$\mathrm{Na}$ literatura, há poucos registros que associam a elevação da temperatura com uma possível redução do 
período de embebição, principalmente nas culturas de valor econômico mais significativo, como é o caso da soja. Isso pode ser explicado pelo fato de a temperatura de $25^{\circ} \mathrm{C}$ ser praticamente padronizada, concentrando, assim, as pesquisas na variação do período de embebição das sementes. No entanto, naquelas culturas em que se busca a adequação do teste de condutividade elétrica, verificou-se que essa relação (temperatura x período de embebição) é mais freqüente. Desse modo, Vanzolini e Nakagawa (1999a) demonstraram diferenciação de nível de vigor entre os lotes de sementes de amendoim, à semelhança da porcentagem de emergência de plântulas em campo, quando associaram o período de embebição de três horas à temperatura de $40^{\circ} \mathrm{C}$. Resultados semelhantes foram verificados por Marques et al. (2002), que, estudando três lotes de sementes de jacarandá, condicionadas nas temperaturas de 20,25 e $30^{\circ} \mathrm{C}$, observaram que a $30^{\circ} \mathrm{C}$ foi possível discriminar os lotes quanto à sua qualidade fisiológica a partir de 12 horas, após 18 horas a $25^{\circ} \mathrm{C}$ e após 24 horas à temperatura de $20^{\circ} \mathrm{C}$. Entretanto, Gaspar e Nakagawa (2002) observaram que não houve diferença entre as temperaturas estudadas $\left(20,25,30,35\right.$ e $\left.40^{\circ} \mathrm{C}\right)$, podendo qualquer uma ser utilizada para a embebição das sementes a serem avaliadas através do teste de condutividade elétrica em sementes de milheto.

Assim, o presente trabalho teve como objetivo verificar o efeito de diferentes temperaturas associado na redução do período de embebição das sementes de soja no teste de condutividade elétrica.

\section{MATERIAL E MÉTODOS}

As sementes dos cultivares Cristalina, Doko-RC, CAC-1 e Emgopa 312 foram multiplicadas no campo experimental Professor Diogo Alves de Mello da UFV no ano agrícola 2001/2002. O ensaio foi constituído de dois blocos com quatro parcelas. As sementes foram colhidas manualmente no estádio de maturação R8 da escala de Fehr e Caviness (1977) e aos 15, 30 e 45 dias após o estádio R8. Após a secagem, foi realizada a debulha das vagens em trilhadeira estacionária e armazenadas em câmara fria à temperatura de $10^{\circ} \mathrm{C}$ e umidade relativa $60 \%$ até o início das avaliações. Os testes de avaliação da qualidade fisiológica foram conduzidos no Laboratório de Análise de Sementes e casa de vegetação da Universidade Federal de Viçosa (UFV).

Para avaliar a possibilidade de redução do período de embebição das sementes de soja, o teste de condutividade elétrica (CE) foi realizado de três maneiras, sendo que a primeira utilizou a metodologia tradicional que consistiu de quatro repetições de 50 sementes para cada tratamento, pesadas com precisão de duas casas decimais e colocadas em copos plásticos $(200 \mathrm{~mL})$ contendo $75 \mathrm{~mL}$ de água destilada. Em seguida foram levadas para germinador na temperatura de $25^{\circ} \mathrm{C}$, em que permaneceram por $24 \mathrm{~h}$. Após esse período, os recipientes foram retirados (16 copos de cada vez) e, com um bastão, as soluções contendo as sementes foram levemente agitadas para uniformização dos lixiviados, e imediatamente procedeu-se à leitura em condutivímetro (Vieira, 1994). Na segunda, cada repetição foi constituída de 20 repetições de 10 sementes, colocadas em copos plásticos com $25 \mathrm{~mL}$ de água destilada e mantidos por 10, 30, 60 e 120 minutos em incubadora tipo BOD, na temperatura de $32^{\circ} \mathrm{C}$. Decorrido cada período de embebição, as sementes foram levemente agitadas para uniformização dos lixiviados e procedeu-se à leitura da condutividade elétrica da solução e, finalmente, na terceira, seguiu-se o mesmo procedimento da metodologia anterior, porém utilizando a temperatura de $40^{\circ} \mathrm{C}$. Nas três metodologias adotou-se o método de massa para medir a condutividade, com sementes não-selecionadas, conforme sugerido por Loeffler et al. (1988). Os resultados foram expressos em $\mu \mathrm{S} . \mathrm{cm}^{-1}$. $\mathrm{g}^{-1}$ de sementes.

$\mathrm{O}$ teste de germinação (TG) e primeira contagem da germinação (PC) consistiram de quatro repetições de 50 sementes por tratamento. As sementes foram distribuídas sobre papel "germitest" previamente umedecido com água destilada, em quantidade equivalente a 2,5 vezes o seu peso seco. Os rolos confeccionados foram mantidos em germinador à temperatura de $25^{\circ} \mathrm{C} \pm 1^{\circ} \mathrm{C}$. As avaliações foram realizadas aos cinco dias (primeira contagem) e aos oito dias após a instalação do teste (contagem final). Foram determinadas as porcentagens de plântulas normais, anormais e sementes mortas, sendo os resultados expressos em \% de plântulas normais, segundo os critérios estabelecidos pelas Regas para Análise de Sementes (Brasil, 1992).

Para o teste de envelhecimento acelerado (EA), foram utilizadas caixas plásticas (gerbox) contendo, ao fundo, $40 \mathrm{~mL}$ de água destilada, nas quais foram colocadas quatro repetições de 50 sementes para cada tratamento, colhidas no ensaio de campo, sobre tela de aço isolando as sementes da água. As caixas foram mantidas em estufa incubadora tipo BOD à temperatura de $42^{\circ} \mathrm{C}$, durante $48 \mathrm{~h}$. (AOSA, 1983). Em seguida, instalou-se o teste de germinação, sendo a avaliação do número de plântulas normais feita aos cinco dias após a instalação do teste, expressando-se os resultados em (\%) porcentagem.

A emergência de plântulas em leito de areia (ELA) foi conduzida em casa de vegetação, utilizando-se bandejas 
plásticas $(27 \times 32 \times 6 \mathrm{~cm})$ contendo areia previamente lavada e tratada com brometo de metila. Foram semeadas cinco repetições de 40 sementes para cada tratamento em cinco sulcos por bandeja. Durante a condução do teste, a temperatura foi registrada duas vezes ao dia (manhã e tarde), discriminando-se as temperaturas máximas e mínimas. Realizaram-se irrigações sempre que necessário. A avaliação e contagem das plântulas normais foram realizadas no décimo segundo dia, quando a maioria das plântulas apresentou o primeiro par de folhas unifolioladas, completamente expandidas.

Os dados foram analisados conforme o modelo experimental de blocos casualizados com parcelas subdivididas, tendo como parcelas às variedades e como subparcelas as épocas de colheita. Nos testes de condutividade elétrica (tradicional e com 20 sub-amostras), a análise de variância foi efetuada separadamente, para cada temperatura e cada período de embebição. Os dados provenientes dos testes de germinação, primeira contagem da germinação, envelhecimento acelerado e emergência de plântulas em leito de areia foram transformados antes das análises estatísticas em arco-seno $(\sqrt{x} / 100)$. Para a expressão dos perfis dos cultivares quanto à qualidade fisiológica das sementes, calcularam-se as médias e os desvios-padrão.

\section{RESULTADOS E DISCUSSÃO}

A Tabela 1 demonstra os resultados obtidos pelos testes de germinação, primeira contagem da germinação, envelhecimento acelerado e emergência em leito de areia. Os quais indicaram que não houve diferenças significativas entre os cultivares e nem interação entre cultivares e épocas de colheita, constatando-se significância somente para o efeito de época. Contudo, há uma tendência, entre os testes, na indicação das sementes do cultivar Cristalina, como de qualidade superior em relação às sementes dos demais.

TABELA 1. Médias obtidas nos testes de germinação, primeira contagem, envelhecimento acelerado e emergência de plântulas em leito de areia em sementes de quatro cultivares de soja, em quatro épocas de colheita ${ }^{1}$

\begin{tabular}{|c|c|c|c|c|}
\hline \multirow{2}{*}{ Cultivar $^{2}$} & Germinação & $\begin{array}{l}\text { Primeira } \\
\text { contagem }\end{array}$ & $\begin{array}{l}\text { Envelhecimento } \\
\text { acelerado }\end{array}$ & Emergência em leito de areia \\
\hline & \multicolumn{4}{|c|}{ (\%) $)_{1}$} \\
\hline Cristalina & $59,93 \mathrm{~A}$ & $58,96 \mathrm{~A}$ & $51,35 \mathrm{~A}$ & $60,42 \mathrm{~A}$ \\
\hline Doko-RC & $58,53 \mathrm{~A}$ & $56,62 \mathrm{~A}$ & $46,76 \mathrm{~A}$ & $57,77 \mathrm{~A}$ \\
\hline CAC-1 & $55,90 \mathrm{~A}$ & $54,52 \mathrm{~A}$ & $43,91 \mathrm{~A}$ & $55,14 \mathrm{~A}$ \\
\hline Emgopa-312 & $54,20 \mathrm{~A}$ & $53,62 \mathrm{~A}$ & $41,20 \mathrm{~A}$ & $54,28 \mathrm{~A}$ \\
\hline $\mathrm{CV}(\%)$ & 19,80 & 17,36 & 16,34 & 8,84 \\
\hline \multicolumn{5}{|c|}{ Épocas de colheita ${ }^{2}$} \\
\hline R8 & $71,82 \mathrm{~A}$ & $70,34 \mathrm{~A}$ & $65,64 \mathrm{~A}$ & $68,95 \mathrm{~A}$ \\
\hline $\mathrm{R} 8+15$ & $63,90 \mathrm{~A}$ & $63,02 \mathrm{~A}$ & $50,91 \mathrm{~B}$ & $60,50 \mathrm{~B}$ \\
\hline $\mathrm{R} 8+30$ & $55,76 \mathrm{~B}$ & $55,06 \mathrm{~B}$ & $42,22 B$ & $53,46 \mathrm{~B}$ \\
\hline $\mathrm{R} 8+45$ & $37,06 \mathrm{C}$ & $35,35 \mathrm{C}$ & $24,45 \mathrm{C}$ & $44,70 \mathrm{C}$ \\
\hline $\mathrm{CV}(\%)$ & 19,80 & 17,36 & 16,34 & 8,84 \\
\hline
\end{tabular}

${ }^{1}$ Os dados foram transformados em Arco-seno $\sqrt{ } \% / 100$ para análise estatística

${ }^{2}$ médias seguidas pela mesma letra na coluna, não diferem entre si pelo Teste de Tukey ao nível de 5\% de probabilidade.

Com relação às épocas de colheita, verificou-se maior porcentagem de germinação e vigor nas sementes colhidas no estádio R8, ocorrendo redução na qualidade fisiológica à medida que as sementes foram permanecendo no campo, atingindo valor mínimo aos 45 dias após R8. Esse comportamento evidencia a influência do ambiente na deterioração das sementes, proporcionada pelo retardamento da colheita, que também foi constatado por outros 
pesquisadores (Vieira et al., 1998; Dias, 1999).

Verificou-se também que, de acordo com o teste empregado, a queda na qualidade das sementes acontece em épocas diferentes. Os testes de germinação e primeira contagem da germinação até 15 dias após a colheita demonstraram que as sementes mantêm sua qualidade inicial. Enquanto, que nos testes de envelhecimento acelerado e emergência em leito de areia são detectadas diferenças no vigor das sementes logo após sua maturidade fisiológica. Esses resultados concordam com Lima (2003), ao constatar que o retardamento da colheita em 15 dias foi eficaz em diferenciar a qualidade fisiológica das sementes de soja.

Vale ressaltar que, embora o teste de germinação possa fornecer informações sobre o desempenho das sementes e a primeira contagem da germinação possa ser considerada um indicativo de vigor, sabe-se que a germinação e a redução da velocidade de germinação não estão entre os primeiros eventos do processo de deterioração de sementes (Delouche; Baskin, 1973).

Considerando o conjunto dos resultados obtidos nos testes de germinação, primeira contagem da germinação, envelhecimento acelerado e emergência de plântulas em leito de areia sobre a qualidade fisiológica das sementes, verificou-se que eles foram eficientes no sentido de acompanhar a evolução do processo de deterioração das sementes dos cultivares, quando estas, foram submetidas à condição adversa de ambiente. Contudo, a sensibilidade, em termos de separação de níveis de viabilidade e vigor, variou com o teste empregado.

Na análise dos resultados do teste condutividade (CE) elétrica (Tabela 2 e 3) também foi verificada, que não houve interação entre os fatores estudados, observando efeitos significativos somente para cultivar e para época. Na Tabela 2 foi verificada que o vigor das sementes avaliado pelo teste de condutividade elétrica variou de acordo com as metodologias estudadas. As sementes dos cultivares Cristalina Doko-RC, de modo geral, apresentaram os mais baixos valores de CE, conseqüentemente, maior vigor em relação às sementes de Emgopa-312 e CAC-1, quando submetidas à embebição por 10,30 e 60 minutos a $32^{\circ} \mathrm{C}$ e 10 e 30 minutos a $40^{\circ} \mathrm{C}$, tendência mostrada pelo testes de caracterização fisiológica. Quando embebidas por 120 minutos a $32^{\circ} \mathrm{C}$ e 60 e 120 minutos a $40^{\circ} \mathrm{C}$ verifica-se que não houve diferença entre os cultivares, indicando que maior tempo de embebição em temperaturas elevadas proporcionou a equiparação de médias, reduzindo a diferença entre nível de vigor das sementes. Nota-se também, que esta aproximação entre as médias foi antecipada quando se elevou a temperatura para $40^{\circ} \mathrm{C}$.

TABELA 2. Condutividade elétrica $(\mu \mathrm{S} / \mathrm{cm} / \mathrm{g})$ da solução de embebição de sementes de quatro cultivares de soja, submetidas a diferentes temperaturas e períodos de embebição

\begin{tabular}{|c|c|c|c|c|c|c|}
\hline \multirow{3}{*}{$\begin{array}{l}\text { Temperatura } \\
\left({ }^{\circ} \mathrm{C}\right)\end{array}$} & \multirow{3}{*}{ Cultivares $^{1}$} & \multicolumn{4}{|c|}{ Teste de condutividade elétrica $(\mu \mathrm{S} / \mathrm{cm} / \mathrm{g})$} & \multirow{3}{*}{$\begin{array}{l}\text { Teste tradicional } \\
\left(25^{\circ} \mathrm{C} / 24 \text { horas }\right)\end{array}$} \\
\hline & & \multicolumn{4}{|c|}{ Períodos de embebição } & \\
\hline & & 10 & 30 & 60 & 120 & \\
\hline \multirow{5}{*}{$32^{\circ} \mathrm{C}$} & Cristalina & $23,44 \mathrm{C}$ & $59,05 \mathrm{~B}$ & $109,66 \mathrm{~B}$ & $181,74 \mathrm{~A}$ & $112,40 \mathrm{BC}$ \\
\hline & Doko-RC & $38,73 \mathrm{BC}$ & $69,51 \mathrm{~B}$ & $117,28 \mathrm{~B}$ & $182,74 \mathrm{~A}$ & $110,13 \mathrm{C}$ \\
\hline & CAC-1 & $36,03 \mathrm{AB}$ & $87,63 \mathrm{~A}$ & $144,33 \mathrm{~A}$ & $215,45 \mathrm{~A}$ & $126,49 \mathrm{AB}$ \\
\hline & Emgopa-312 & $38,40 \mathrm{~A}$ & $86,24 \mathrm{~A}$ & $140,67 \mathrm{~A}$ & $214,23 \mathrm{~A}$ & $131,91 \mathrm{~A}$ \\
\hline & $\mathrm{CV}(\%)$ & 8,76 & 8,77 & 9,76 & 9,60 & 5,09 \\
\hline \multirow{5}{*}{$40^{\circ} \mathrm{C}$} & Cristalina & $28,58 \mathrm{C}$ & $80,08 \mathrm{~B}$ & $155,62 \mathrm{~A}$ & $248,30 \mathrm{~A}$ & \\
\hline & Doko-RC & $33,02 \mathrm{BC}$ & $85,90 \mathrm{~B}$ & $156,76 \mathrm{~A}$ & $243,03 \mathrm{~A}$ & \\
\hline & CAC-1 & $45,22 \mathrm{AB}$ & $115,13 \mathrm{~A}$ & $194,49 \mathrm{~A}$ & $290,58 \mathrm{~A}$ & \\
\hline & Emgopa-312 & $48,72 \mathrm{~A}$ & $110,84 \mathrm{~A}$ & $186,99 \mathrm{~A}$ & $295,87 \mathrm{~A}$ & \\
\hline & $\mathrm{CV}(\%)$ & 13,03 & 10,18 & 11,89 & 14,20 & \\
\hline
\end{tabular}

${ }^{1}$ médias seguidas pela mesma letra na coluna, não diferem entre si pelo Teste de Tukey ao nível de 5\% de probabilidade 
Na tabela 3 observa-se que menores valores de condutividade elétrica foram obtidos para as sementes colhidas no estádio R8 e os mais elevados, aos 45 dias após R8. Os maiores valores de CE nas últimas épocas de colheita, principalmente aos 45 dias após o estádio R8, estão relacionados à redução no vigor das sementes, concordando com as evidências de que o processo de deterioração das sementes está relacionado com a perda do vigor e alteração na integridade das membranas celulares, por meio do aumento da lixiviação de constituintes celulares orgânicos e inorgânicos (Pereira e Andrews, 1982).

TABELA 3. Condutividade elétrica $(\mu \mathrm{S} / \mathrm{cm} / \mathrm{g})$ da solução de embebição de sementes de soja colhidas em quatro épocas, submetidas a diferentes temperaturas e períodos de embebição

\begin{tabular}{|c|c|c|c|c|c|c|}
\hline \multirow{3}{*}{$\begin{array}{c}\text { Temperatura } \\
\left({ }^{\circ} \mathrm{C}\right)\end{array}$} & \multirow{3}{*}{$\begin{array}{l}\text { Épocas de } \\
\text { colheita }^{1}\end{array}$} & \multicolumn{4}{|c|}{ Teste de condutividade elétrica $(\mu \mathrm{S} / \mathrm{cm} / \mathrm{g})$} & \multirow{3}{*}{$\begin{array}{l}\text { Teste tradiciona } \\
\left(25^{\circ} \mathrm{C} / 24 \text { horas }\right)\end{array}$} \\
\hline & & \multicolumn{4}{|c|}{ Período de embebição ( minutos) } & \\
\hline & & 10 & 30 & 60 & 120 & \\
\hline \multirow{5}{*}{$32^{\circ} \mathrm{C}$} & $\mathrm{R} 8$ & $23,94 \mathrm{~B}$ & $61,62 \mathrm{~B}$ & $108,53 \mathrm{C}$ & $165,05 \mathrm{C}$ & $95,56 \mathrm{C}$ \\
\hline & $\mathrm{R} 8+15$ & $31,05 \mathrm{AB}$ & $64,79 \mathrm{~A}$ & $127,09 \mathrm{~B}$ & $194,07 \mathrm{~B}$ & $122,16 \mathrm{~B}$ \\
\hline & $\mathrm{R} 8+30$ & $33,56 \mathrm{~A}$ & $78,86 \mathrm{~A}$ & $131,52 \mathrm{AB}$ & $205,03 \mathrm{AB}$ & $124,64 \mathrm{AB}$ \\
\hline & $\mathrm{R} 8+45$ & $38,05 \mathrm{~A}$ & $87,66 \mathrm{~A}$ & $144,81 \mathrm{~A}$ & $229,64 \mathrm{~A}$ & $138,58 \mathrm{~A}$ \\
\hline & $\mathrm{CV}(\%)$ & 8,76 & 8,77 & 9,76 & 9,60 & 5,09 \\
\hline \multirow{5}{*}{$40^{\circ} \mathrm{C}$} & $\mathrm{R} 8$ & $229,73 B$ & $81,92 \mathrm{~B}$ & $150,40 \mathrm{~B}$ & $225,15 B$ & \\
\hline & $\mathrm{R} 8+15$ & $38,34 \mathrm{AB}$ & $98,87 \mathrm{AB}$ & $175,97 \mathrm{~A}$ & $269,29 \mathrm{AB}$ & \\
\hline & $\mathrm{R} 8+30$ & $41,38 \mathrm{~A}$ & $101,22 \mathrm{~A}$ & $178,17 \mathrm{~A}$ & $276,99 \mathrm{~A}$ & \\
\hline & $\mathrm{R} 8+45$ & $46,10 \mathrm{~A}$ & $109,94 \mathrm{~A}$ & $189,32 \mathrm{~A}$ & $306,35 \mathrm{~A}$ & \\
\hline & $\mathrm{CV}(\%)$ & 13,03 & 10,18 & 11,89 & 14,20 & \\
\hline
\end{tabular}

${ }^{1}$ médias seguidas pela mesma letra na coluna, não diferem entre si pelo Teste de Tukey ao nível de 5\% de probabilidade.

Verificou-se também que, nas metodologias estudadas, houve aumento progressivo nos valores da condutividade com o decorrer do período de embebição, fato também constatado em sementes de soja por Loeffler et al. (1988); Marcos Filho et al. (1990); Dias e Marcos Filho (1996). É importante notar que a liberação mais intensa ocorreu quando se elevou a temperatura para $40^{\circ} \mathrm{C}$ (Tabela 3), o que se mostra coerente com as observações de Vanzolini e Nakagawa (1999) e Gaspar e Nakagawa (2002).

Quanto à possibilidade de redução do período de embebição das sementes, verificou-se, de modo geral, semelhança entre os resultados obtidos nas duas metodologias estudadas (condutividade a 32 e a $40^{\circ} \mathrm{C}$ ) e, destas, com a metodologia tradicional $\left(25^{\circ} \mathrm{C}\right.$ por 24 horas), principalmente, quando se estudou o efeito de época.

Assim, verifica-se que com o uso de 10 minutos a $32^{\circ} \mathrm{C}$ (Tabela 2), houve maior discriminação entre as sementes dos diferentes cultivares, separando-os em três níveis distintos de vigor. Esse período indicou maior e menor vigor de Cristalina e Emgopa-312, respectivamente, enquanto os cultivares
Doko-RC e CAC-1, que não diferiram entre si, apresentaram valores intermediários de condutividade elétrica. A partir dos 30 e 60 minutos a diferença entre cultivares é reduzida a dois grupos distintos de vigor, indicando as sementes de Cristalina e Doko-RC como as mais vigorosas em relação às de CAC-1 e Emgopa-312. Aos 120 minutos desaparece essa diferença, igualando os mesmos quanto ao nível de vigor. Comportamento semelhante foi verificado quando se elevou a temperatura para $40^{\circ} \mathrm{C}$, sendo que esse agrupamento de médias é verificado mais rapidamente, ou seja, aos 60 minutos, enquanto a $32^{\circ} \mathrm{C}$ esse comportamento foi verificado aos 120 .

Verificou-se ainda que o período de 10 minutos, tanto a $32^{\circ} \mathrm{C}$ como a 40 , apresentou ordem de classificação dos cultivares mais próxima da obtida com 24 horas por $25^{\circ} \mathrm{C}$ em relação aos outros períodos estudados, por outro lado, quando se estudou o efeito de época os resultados encontrados aos 60 e 120 minutos a $32^{\circ} \mathrm{C}$ foram idênticos aos da metodologia tradicional. Vanzolini e Nakagawa (1999a), em sementes de amendoim, utilizando a temperatura de $40^{\circ} \mathrm{C}$, conseguiram 
reduzir de 24 para 3 horas o tempo de embebição.

Esses resultados divergem dos constatados por Loeffler et al. (1988), Marcos Filho et al. (1990) e Dias e Marcos Filho (1996) em que foram necessários períodos mais longos para separação eficiente de lotes de sementes de soja. Contudo, vale ressaltar que os referidos autores utilizaram temperaturas de 20 e $25^{\circ} \mathrm{C}$, o que permitiu deduzir, no presente trabalho, que a elevação da temperatura antecipou a separação dos cultivares quanto ao vigor, e os períodos prolongados propiciaram a estabilização de lixiviação das sementes, levando à concentração das médias e, conseqüentemente, aproximando os cultivares quanto ao vigor das sementes.

A análise global indicou que, em todos os testes, a qualidade das sementes declinou progressivamente com o retardamento da colheita. Em geral, as metodologias de condutividade empregadas foram eficientes na avaliação da qualidade das sementes de soja, indicando que há possibilidade de redução do período de embebição no teste de condutividade elétrica. Analisando a sensibilidade dos períodos de embebição em detectar diferenças entre nível de vigor de sementes, destaca-se os períodos de 60 e 120 minutos $/ 32^{\circ} \mathrm{C}$ que discriminou a qualidade das sementes de soja sob o efeito de época de forma idêntica àquela observada no método tradicional $\left(25^{\circ} \mathrm{C} / 24 \mathrm{~h}\right)$. Contudo, independentemente da combinação temperatura/período de embebição utilizada, as informações fornecidas pelas duas metodologias indicaram que todos os períodos forneceram indicações consistentes sobre a qualidade das sementes.

Em geral, os resultados indicaram que é possível reduzir o tempo de embebição das sementes de soja em períodos inferiores a 24 horas nesse teste e, assim, possibilitar o descarte de lotes de qualidade inferior. A possibilidade de redução no tempo de embebição das sementes para avaliação da condutividade elétrica já havia sido verificada com soja por Loeffler et al. (1988), Marcos-Filho et al. (1990) e Dias e Marcos Filho (1996); em outras espécies como amendoim, por Vanzolini e Nakakawa (1999ab), girassol, por Brandão Jr. et al. (1997) e Albuquerque et al. (2001); milheto, por Gaspar e Nakagawa (2002); tomate, por Rodo et al. (1998) e Sá (1999); e também feijão-vagem e quiabo, por Dias et al. (1998).

\section{CONCLUSÕES}

A elevação da temperatura de embebição no teste de condutividade elétrica diminui o tempo de embebição para identificação de sementes de soja com diferentes níveis de vigor.
O teste de condutividade elétrica a 32 ou 40 oC por $10,30,60$ ou 120 minutos é eficiente na avaliação rápida da qualidade das sementes de soja com diferentes níveis de vigor.

O período de 10 minutos para embebição das sementes de soja a 32 ou 40oC já possibilita a separação, em curto período de tempo, de lotes de sementes pelo teste de condutividade elétrica.

As combinações 120 minutos $/ 32^{\circ} \mathrm{Ce} \quad 60 \mathrm{e} 120$ minutos $/ 40^{\circ} \mathrm{C}$ discriminaram lotes de sementes à semelhança do método tradicional $\left(24 \mathrm{horas} / 25^{\circ} \mathrm{C}\right)$.

\section{REFERÊNCIAS}

ALBUQUERQUE, M. C. F. et al. Teste de condutividade elétrica e de lixiviação de potássio na avaliação da qualidade fisiológica de sementes de girassol. Revista Brasileira de Sementes, v. 23, n. 1, p. 1-8, 2001.

ALVAREZ, P. J. C. et al. Relationship between soybean seed coat lignin content and resistance to mechanical damage. Seed Sciece and Technology, v. 25, n. 2, p. 209-214, 1997.

ASSOCIATION OF OFFICIAL SEED ANALYSTS-AOSA. Seed vigor testing handbook. [S.l.]: AOSA, 1983. 93 p. (Contribution, 32).

BEWLEY, J. D. Membrane changes in seeds as related to germination and the perturbations resulting from deterioration in storage. In: Mc DONALD JR., M.B.; NELSON, C. J. (Ed.). Physiology of seed deterioration. Madison: CSSA, 1986. p. 27-45.

BRACCINI, A. L. et al. Avaliação da qualidade fisiológica e sanitária da semente de genótipos de soja (Glycine max (L.) Merrill) com diferentes graus de impermeabilidade do tegumento. Revista Brasileira de Sementes, v. 16, n. 2, p. 195-200, 1994b.

BRANDÃO JR., D.S. et al. Adequação do teste de condutividade elétrica para determinar a qualidade fisiológica de sementes de girassol. Informativo ABRATES, v. 7, n. 1/2, p. 184, 1997.

BRASIL. Ministério da Agricultura. Regras para análise de sementes. Brasília: Secretaria Nacional de Defesa Agropecuária, 1992. 365 p.

BRUGGINK, H. et al. Some factors influencing electrolyte leakage from maize (Zea mays l.) Kernels. Seed Science Research, v. 1, n. 1, p. 15-20, 1991.

CALIARI, M.F.; MARCOS FILHO, J. Comparação entre métodos para avaliação da qualidade fisiológica de sementes de ervilha (Pisum sativum L.). Revista Brasileira de 
Sementes, v. 12, n. 3, p. 52-75. 1990.

COSTA, A. F. S. Avaliação da qualidade fisiológica das sementes de genótipos de soja (Glycine max (L.) Merrill), produzidas em cinco localidades do Estado de Minas Gerais. Viçosa, MG: UFV, 1986. 110 f. Dissertação (Mestrado em Fitotecnia) - Universidade Federal de Viçosa, Viçosa.

DELOUCHE, J. C.; BASKIN, C. C. Accelerated aging techniques for predicting the relative storability of seed lots. Seed Science and Technology, v. 1, n. 2, p. 427-52, 1973.

DIAS, A.C.P. Atividade de lipoxigenases durante a germinação e qualidade fisiológica de sementes de soja. Viçosa, MG: UFV, 67 f. 1999. Dissertação (Mestrado em Fitotecnia) - Universidade Federal de Viçosa, Viçosa.

DIAS, D. C. F. S.; MARCOS FILHO, J. Testes de condutividade elétrica para avaliação do vigor de sementes de soja (Glycine max (L.) Merrill). Scientia Agrícola, v. 53, n. 1, p. 1-11, 1996.

DIAS, D. C. F.; VIEIRA, A. N.; BHERING, M. C. Condutividade elétrica e lixiviação de potássio para avaliação do vigor de sementes de hortaliças: feijão-vagem e quiabo. Revista Brasileira de Sementes, v. 20, n. 2, p. 408-413, 1998.

FEHR, W. R.; CAVINNESS, C. E. Stages of soybean development. low St. Un. Ames lowa: Cooperative Extension Service, 1977. 12 p.

GASPAR, C. M.; NAKAGAWA, J. Teste de condutividade elétrica em função do período e da temperatura de embebição para sementes de milheto. Revista Brasileira de Sementes, v. 24, n. 2, p. 82-89, 2002 b.

HAMPTON, J. G.; JOHNSTONE, K. A.; EUA-UMPON, V. Bulk conductivity test variables for mungbean, soybean and French bean seed lots. Seed Science and Technology, v. 20, n. 3, p. 677-686, 1992.

HAMPTON, J.G.; LUNGWANGWA, A.L.; HILL, K.A. The bulk conductivity test for Lotus seed lots. Seed Science and Technology, v. 22, p. 177-180, 1994.

HAMPTON, J. G.; TEKRONY, D. M. Handbook of vigour test methods. Zurich: International Seed Testing Association, 1995. $117 \mathrm{p}$.

KRZYZANOWSKI, F. C.; FRANÇA NETO, J. B.; HENNING, A. A. Relato dos testes de vigor disponíveis para as grandes culturas. Informativo ABRATES, Londrina, v. 1, n. 2, p. 15-50, 1991.

LEOPOLD, A. A. Temperature effects on soybean imbibition and leakage. Plant Physiology, v. 65, n. 4, p. 1096-8, 1980
LIMA, V. A. A. Qualidade fisiológica de sementes de soja com alteração na composição de ácidos graxos e ausência de lipoxigenase. 2003. 678 f. Tese (Doutorado em Fitotecnia) - Universidade Federal de Viçosa, Viçosa.

LOEFFLER, L. M.; TEKRONY, D. M.; EGLI, D. B. The bulk conductivity test as an indicator of soybean seed quality. Journal of Seed Technology, v. 12, n. 1, p. 37-53, 1988.

MARCOS FLHO, J. et al. Estudo comparativo de métodos para a avaliação da qualidade fisiológica de sementes de soja, com ênfase ao teste de condutividade elétrica. Pesquisa Agropecuária Brasileira, v. 25, n. 12, p. 1805-15, 1990.

MARQUES, M. A.; PAULA, R. C.; RODRIGUES, T. J. D. Adequação do teste de condutividade elétrica para determinar a qualidade fisiológica de sementes de jacarandáda-bahia (Dalbergia nigra (Vell.) Fr. All. ex Benth.). Revista Brasileira de Sementes, v. 24, n. 1, p. 271-278, 2002 b.

MURPHY, J. B.; NOLAND, T. L. Temperature effects on seed imbibition and leakage mediated by viscosity and membranes. Plant Physiology, v. 69, n. 2, p. 428-431, 1982.

PANOBIANCO, M.; VIEIRA, R. D. Electrical conductivity of soybean soaked seeds. I. Effect of genotype. Pesquisa Agropecuária Brasileira, v. 31, n. 9, p. 621-7, 1996.

PEREIRA, L. A. G.; ANDREWS, C. H. Carbohydrate leachates and electrical conductivity meassurementes in soybean seeds. Agronomy Abstracts, v. 135, 1982.

POWELL, A. A. Cell membranes and seed leanchate conductivity in relation to the quality of seed for sowing. Journal of Seed Tecnology. v. 10, n. 2, p. 81-100, 1986.

RODO, A. B. et al. Teste de condutividade elétrica em sementes de tomate. Revista Brasileira de Sementes, v. 20, n. 1, p. 29-38. 1998.

ROSA, S. D. V. F. et al. Eficácia do teste de condutividade elétrica para uso em estudos de danos de secagem em sementes de milho. Revista Brasileira de Sementes, v. 22, n. 1., p. 54-63, 2000.

SÁ, M. E. Condutividade elétrica em sementes de tomate (Lycopersicon lycopersicum L.). Scientia Agrícola v. 56, n. 1, p. 1-9, 1999.

SIMON, E. W.; RAJA HARUM, R. M. Leakage during seed imbibition. Journal of Experimental Botany, v. 23, n. 77, p. 1076-85, 1972.

TAO, K. J. Vigour referee test for soybean and corn. AOSA Newsletter, v. 54, p. 40-58, 1980.

VANZOLINI, S.; NAKAGAWQA, J. Teste de condutividade 
elétrica em sementes de amendoim: efeitos de temperatura e de período de embebição. Revista Brasileira de Sementes, v. 21, n. 1, p. 41-45, 1999a.

VANZOLINI, S.; NAKAGAWQA, J. Teste de condutividade elétrica em sementes de amendoim: efeitos de teor de água inicial e de período de embebição. Revista Brasileira de Sementes, v. 21, n. 1, p. 46-52, 1999b.

VIEIRA, R. D. Teste de condutividade elétrica. In: VIEIRA, R. D.; CARVALHO, N. M.; SADER, R. Teste de vigor em sementes. Jaboticabal: FUNEP, 1994, p. 103-32.
VIEIRA, R. D. et al. Comportamento de cultivares de soja quanto a qualidade fisiológica de sementes. Pesquisa Agropecuária Brasileira, v. 33, n. 2, p. 123-130, 1998.

VIEIRA, R. D.; KRZYZANOWSKI, F. C. Teste de condutividadeelétrica.In:VIEIRA,R.D.;KRZYZANOWSKI, F. C.; FRANÇA NETO, J. B. (Ed.). Vigor de sementes: conceitos e testes. Londrina, PR: ABRATES, 1999. cap. 4, p. $1-26$.

VIEIRA, R. D. et al. Condutividade elétrica e teor de água inicial das sementes de soja. Pesquisa Agropecuária Brasileira, v. 37, p. 1333-1338, 2002. 